\title{
Selective loss of glucose-induced amplification of insulin secretion in mouse pancreatic islets pretreated with sulfonylurea in the absence of fuels
}

Received: 3 June 2005 / Accepted: 3 August 2005 / Published online: 11 November 2005

(C) Springer-Verlag 2005

\begin{abstract}
Aims/hypothesis: The beta cell metabolism of glucose, and some other fuels, initiates insulin secretion by closure of ATP-sensitive $\mathrm{K}^{+}$channels and amplifies the secretory response via unknown metabolic intermediates. The aim of this study was to further characterise the mechanism responsible for the metabolic amplification of insulin secretion. Materials and methods: Pancreatic islets were isolated from albino mice by collagenase digestion. Insulin secretion in perifused islets was determined by ELISA. Bioluminometry was used to determine the ATP and ADP content of the incubated islets. Results: After perifusing islets for $60 \mathrm{~min}$ with $2.7 \mu \mathrm{mol} / \mathrm{l}$ glipizide (closing all ATP-sensitive $\mathrm{K}^{+}$channels) in the absence of any fuel, perifusion with a test medium containing $2.7 \mu \mathrm{mol} / 1$ glipizide plus $30 \mathrm{mmol} / 1$ glucose did not enhance insulin secretion. However, test media supplemented with $2.7 \mu \mathrm{mol} / 1$ glipizide plus either $10 \mathrm{mmol} / \mathrm{l} \alpha$-ketoisocaproate or $10 \mathrm{mmol} / 1$ 2-aminobicyclo[2,2,1]heptane-2-carboxylic acid amplified the glipizide-induced insulin secretion. In pancreatic islets preincubated for $60 \mathrm{~min}$ with $2.7 \mu \mathrm{mol} / 1$ glipizide in the absence of any fuel, $40 \mathrm{~min}$ incubations in the presence of $2.7 \mu \mathrm{mol} / 1$ glipizide plus $30 \mathrm{mmol} / 1$ glucose or plus $10 \mathrm{mmol} / \mathrm{l} \alpha$-ketoisocaproate produced an increase in the ATP content, no change in the ADP content and a rather small increase in the ATP:ADP ratio. The corresponding effects of glucose and $\alpha$-ketoisocaproate were similar. Conclusions/interpretation: These results suggest that metabolic amplification of fuel-induced insulin secretion is not mediated by changes in the beta cell content of ATP and ADP, but might be due to export of citrate cycle intermediates to the beta cell cytosol.
\end{abstract}

K. A. Urban · U. Panten $(\bowtie)$

Institute of Pharmacology and Toxicology,

Braunschweig Technical University,

Mendelssohnstrasse 1,

38106 Braunschweig, Germany

e-mail: u.panten@tu-bs.de

Tel.: +49-531-3915669

Fax: +49-531-3918182
Keywords Amplification - ATP content - Glucose Insulin secretion $\cdot \alpha$-Ketoisocaproate

Abbreviation BCH: 2-aminobicyclo[2,2,1]heptane-2carboxylic acid

\section{Introduction}

It is generally believed that glucose, and some other fuels, initiate insulin release by increasing ATP levels and decreasing ADP levels in the beta cell cytosol [1-3]. The resulting inhibition of the ATP-sensitive $\mathrm{K}^{+}$channels in the beta cell plasma membrane stimulates a chain of events that trigger the exocytosis of insulin. As soon as insulin release is initiated, the secretory response is enhanced by an amplifying pathway that requires the metabolism of the fuel secretagogue [1]. The nature of the amplifying signal is unclear. An increase in the cytosolic ATP:ADP ratio [1], the export of citrate cycle intermediates to the cytosol (cataplerosis) [3], and the accumulation of cytosolic lipids $[4,5]$ might be involved in the amplification process. Therefore, the present study aimed to further characterise the mechanism by which the metabolic amplification of insulin secretion occurs.

\section{Materials and methods}

Materials and media

Sigma (Taufkirchen, Germany) provided the sodium salt of $\alpha$-ketoisocaproate (4-methyl-2-oxopentanoate), 2-aminobicyclo[2,2,1]heptane-2-carboxylic acid (BCH; about $90 \%$ as the racemate of the endo-isomer), monomethyl succinate (succinic acid monomethyl ester) and the ATP bioluminescent assay kit (FL-AA). Phosphoenolpyruvate and pyruvate kinase were from Roche (Mannheim, Germany). All other chemicals were obtained from sources described elsewhere [6]. The medium for isolation, perifusion and incubation of pancreatic islets consisted of basal medium 
supplemented with $2 \mathrm{mg} / \mathrm{ml}$ BSA [6]. For blocking of ATP-sensitive $\mathrm{K}^{+}$channels in beta cells, some media were supplemented with the potent sulfonylurea glipizide (which acts more rapidly than glibenclamide) at a concentration of $2.7 \mu \mathrm{mol} / \mathrm{l}$, which corresponds to a free concentration of about $2 \mu \mathrm{mol} / 1$ in the presence of $2 \mathrm{mg} / \mathrm{ml} \mathrm{BSA} \mathrm{[6].} \mathrm{This} \mathrm{free} \mathrm{glipizide} \mathrm{concentration} \mathrm{en-}$ sures complete closure of all ATP-sensitive $\mathrm{K}^{+}$channels, since it is 200-fold higher than the concentration at which $50 \%$ of the sulfonylurea receptor sites of the beta cell ATP-sensitive $\mathrm{K}^{+}$channels are occupied by glipizide [6]. Other additions to the media are detailed below.

\section{Measurement of insulin secretion}

Albino mice (NMRI) were purchased from commercial breeders (Harlan Winkelmann, Borchen, Germany, and Charles River, Sulzfeld, Germany) and were bred at the Animal Breeding Center, Braunschweig Technical University (Braunschweig, Germany). Pancreatic islets from mice of both sexes (9-13 weeks old, fed an unrestricted diet) were isolated by collagenase digestion (in the presence of $5 \mathrm{mmol} / 1$ glucose), and batches of 50 islets were perifused with the desired medium at a flow rate of $0.9 \mathrm{ml} / \mathrm{min}$ and a temperature of $37^{\circ} \mathrm{C}$ [6]. The insulin contents of fractions collected over periods of 1 or $4 \mathrm{~min}$ duration were determined using an ELISA (Mercodia, Uppsala, Sweden), with rat insulin used as reference. The tested compounds did not influence the assay.

\section{Measurement of ATP and ADP content of islets}

In isolated mouse islets (for details see above), ATP and ADP were determined by a modification of a published method [7]. Batches of 15 islets were preincubated in $200 \mu \mathrm{l}$ of control medium (either in the absence of secretagogue or in the presence of $2.7 \mu \mathrm{mol} / \mathrm{l}$ glipizide) for $60 \mathrm{~min}$ at $37^{\circ} \mathrm{C}$ (control period). Following preincubation, $90 \%$ of the medium was replaced with control medium or with medium plus test compound, and the cells incubated for $40 \mathrm{~min}$ at $37^{\circ} \mathrm{C}$. Incubations were stopped by the addition of $100 \mu \mathrm{l}$ of trichloroacetic acid (15\%). Each sample was then mixed by vortex, left on ice for $5 \mathrm{~min}$, and centrifuged for $5 \mathrm{~min}$ at $3,000 \times g$. The trichloroacetic acid in $240 \mu \mathrm{l}$ of the supernatant was removed by repeated mixing with $900 \mu$ of diethylether saturated with water [7]. After addition of $240 \mu \mathrm{l}$ of buffer $\left(20 \mathrm{mmol} / \mathrm{l} \mathrm{HEPES}, 3 \mathrm{mmol} / \mathrm{l} / \mathrm{MgCl}_{2}, \mathrm{pH}\right.$ 7.75), the neutralised extract was kept at $-70^{\circ} \mathrm{C}$. ATP and the sum of ATP plus ADP (ADP calculated by difference) were measured in aliquots of this extract as described previously [7], with minor modifications, using a bioluminescence assay kit (Sigma), well plates and a Wallac 1420 system (PerkinElmer, Boston, MA, USA). ATP and ADP standards were run through the entire procedure, including the extraction steps.

\section{Statistical analysis}

Results are presented as means \pm SEM. Differences between groups were analysed using the Wilcoxon matchedpairs signed-ranks test (two-tailed) or the Mann-Whitney $U$ test (two-tailed). A $p$ value less than 0.05 was considered significant.

\section{Results}

After perifusing isolated pancreatic islets from mice for $60 \mathrm{~min}$ in the absence of any fuel or secretagogue, application of $30 \mathrm{mmol} / \mathrm{l}$ glucose produced a biphasic increase in insulin secretion (Fig. 1a). The secretory rates at the peak of the first phase and at the end of the test period (min 102) were 7.6-fold and 22.4-fold higher, respectively, than the rate at the end of the control period. The perifusion of pancreatic islets in the presence of $2.7 \mu \mathrm{mol} / 1$ glipizide (blocking all ATP-sensitive $\mathrm{K}^{+}$channels) for $60 \mathrm{~min}$ induced a 2.5 -fold increase in the secretory rate relative to perifusion with basal medium alone $(p<0.001$, MannWhitney $U$ test) (Fig. 1a). Surprisingly, the perifusion of

Table 1 Effects of glucose and $\alpha$-ketoisocaproate on the content of ATP and ADP and the ATP:ADP ratio in mouse islets incubated with or without $2.7 \mu \mathrm{mol} / \mathrm{l}$ glipizide

\begin{tabular}{|c|c|c|c|c|c|c|c|c|}
\hline \multirow[b]{2}{*}{ Parameter } & \multicolumn{2}{|c|}{-Glipizide } & \multicolumn{2}{|c|}{-Glipizide } & \multicolumn{2}{|c|}{ +Glipizide } & \multicolumn{2}{|c|}{ +Glipizide } \\
\hline & Control & Test & Control & Test & Control & Test & Control & Test \\
\hline Glucose (mmol/l) & 0 & 30 & 0 & 0 & 0 & 30 & 0 & 0 \\
\hline $\mathrm{KIC}(\mathrm{mmol} / \mathrm{l})$ & 0 & 0 & 0 & 10 & 0 & 0 & 0 & 10 \\
\hline ATP (pmol per islet) & $7.5 \pm 0.8$ & $9.8 \pm 0.9^{b}$ & $8.1 \pm 0.3$ & $9.0 \pm 0.4^{\mathrm{a}}$ & $8.3 \pm 0.5$ & $9.7 \pm 0.6^{\mathrm{a}}$ & $8.1 \pm 0.5$ & $9.4 \pm 0.7^{\mathrm{b}}$ \\
\hline ADP (pmol per islet) & $3.2 \pm 0.4$ & $2.6 \pm 0.3^{\mathrm{a}}$ & $3.3 \pm 0.2$ & $2.4 \pm 0.2^{\mathrm{b}}$ & $3.6 \pm 0.3$ & $3.5 \pm 0.2$ & $3.4 \pm 0.3$ & $3.4 \pm 0.3$ \\
\hline ATP:ADP ratio & $2.4 \pm 0.1$ & $3.9 \pm 0.2^{\mathrm{b}}$ & $2.5 \pm 0.1$ & $3.9 \pm 0.2^{\mathrm{b}}$ & $2.4 \pm 0.1$ & $2.8 \pm 0.1^{\mathrm{b}}$ & $2.5 \pm 0.2$ & $2.9 \pm 0.2^{\mathrm{b}}$ \\
\hline$n$ & 9 & 9 & 9 & 9 & 11 & 11 & 11 & 11 \\
\hline
\end{tabular}

Values are means \pm SEM of results from separate experiments. Each of the four experimental series consisted of simultaneous incubations (40 $\mathrm{min})$ in the absence (control) or presence (test) of glucose $(30 \mathrm{mmol} / \mathrm{l})$ or $\alpha$-ketoisocaproate (KIC, $10 \mathrm{mmol} / \mathrm{l})$. During the preincubations $(60 \mathrm{~min})$ and incubations, glipizide $(2.7 \mu \mathrm{mol} / \mathrm{l})$ was absent $(-$ Glipizide) or present $(+\mathrm{Glipizide})$

${ }_{p}<0.05$, for test vs corresponding control

${ }^{b} p<0.01$, for test vs corresponding control 
a

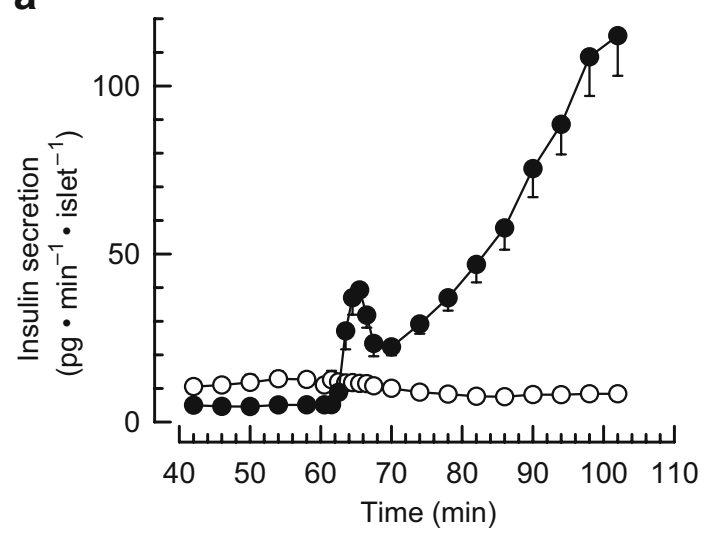

b

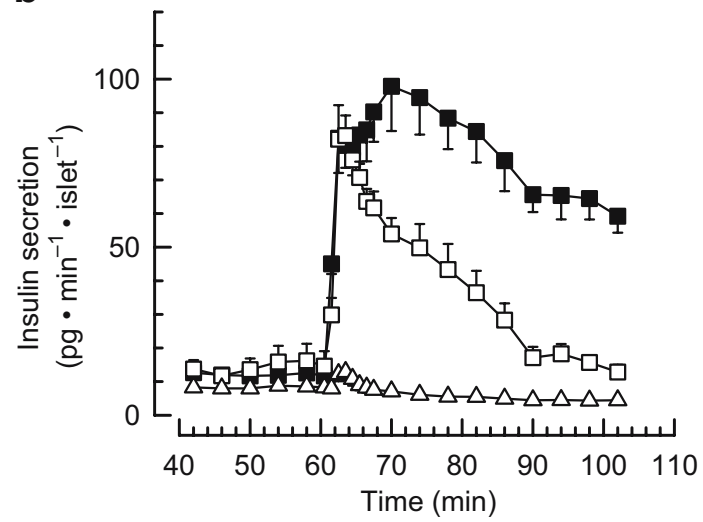

Fig. 1 Effects of glucose, $\alpha$-ketoisocaproate, $\mathrm{BCH}$, and monomethyl succinate on the kinetics of insulin secretion by mouse pancreatic islets. Data points are means from separate experiments (with SEM shown when larger than symbols) and are depicted in the middle of the sampling intervals. a Islets were perifused from time 0 $(t=0)$ to time $60 \mathrm{~min}(t=60)$ with medium containing no fuel or secretagogue (control period) and from $t=61$ to $t=104$ with medium containing $30 \mathrm{mmol} / 1$ glucose (filled circles, $n=8$ ), or were perifused from $t=0$ to $t=60$ with medium containing $2.7 \mu \mathrm{mol} / 1$ glipizide (control period) and from $t=61$ to $t=104$ with medium containing $2.7 \mu \mathrm{mol} / 1$ glipizide plus $30 \mathrm{mmol} / 1$ glucose (open circles, $n=7$ ). b Islets were perifused from $t=0$ to $t=60$ with medium containing $2.7 \mu \mathrm{mol} / 1$ glipizide (control period) and from $t=61$ to $t=104$ with medium containing $2.7 \mu \mathrm{mol} / \mathrm{l}$ glipizide plus one of the following: $10 \mathrm{mmol} / 1 \alpha$-ketoisocaproate (filled squares, $n=6$ ), $10 \mathrm{mmol} / \mathrm{l} \mathrm{BCH}$ (open squares, $n=6$ ), or $10 \mathrm{mmol} / 1$ monomethyl succinate (open triangles, $n=5$ )

islets with a medium containing $2.7 \mu \mathrm{mol} / \mathrm{l}$ glipizide plus $30 \mathrm{mmol} / \mathrm{l}$ glucose following this control period did not enhance insulin secretion (Fig. 1a). However, substitution of the glucose in the glipizide-containing test medium with $10 \mathrm{mmol} / \mathrm{l} \alpha$-ketoisocaproate, $10 \mathrm{mmol} / \mathrm{l} \mathrm{BCH}$ (non-metabolisable leucine analogue; containing about $4.5 \mathrm{mmol} / \mathrm{l}$ of the effective (-) endo-isomer), or $10 \mathrm{mmol} / \mathrm{l}$ monomethyl succinate (medium $\mathrm{pH}$ adjusted with $\mathrm{NaOH}$ )caused monophasic increases in secretory rates (Fig. 1b). The peak rates were 7.8-, 5.1- and 1.6-fold higher, respectively, than the rate at the end of the control period (Fig. 1b). Secretory rates were higher than that rate at time $58 \mathrm{~min}(t=58)$ from $t=61.5$ to $t=102$ for every experiment with $\alpha$-ketoisocaproate, from $t=61.5$ to $t=86$ for every experiment with $\mathrm{BCH}$, and from $t=62.5$ to $t=63.5$ for every experiment with monomethyl succinate.

After preincubating pancreatic islets for $60 \mathrm{~min}$ in the absence of any fuel or secretagogue, 40-min incubations in the presence of $30 \mathrm{mmol} / \mathrm{l}$ glucose or $10 \mathrm{mmol} / \mathrm{l} \alpha$-ketoisocaproate increased the ATP content and the ATP:ADP ratio and decreased the ADP content in the islets (Table 1). The extent of the changes (test minus control) was similar for glucose and $\alpha$-ketoisocaproate ( $p>0.05$, Mann-Whitney $U$ test). After preincubating pancreatic islets for $60 \mathrm{~min}$ in the absence of fuel but in the presence of $2.7 \mu \mathrm{mol} / 1$ glipizide, $40-\mathrm{min}$ incubations in the presence of $2.7 \mu \mathrm{mol} / 1$ glipizide plus $30 \mathrm{mmol} / \mathrm{l}$ glucose or $2.7 \mu \mathrm{mol} / \mathrm{l}$ glipizide plus $10 \mathrm{mmol} / \mathrm{l} \alpha$-ketoisocaproate produced an increase in the ATP content, no change in the ADP content, and a rather small increase in the ATP:ADP ratio (Table 1). Changes (test minus control) of similar magnitude were observed for both glucose and $\alpha$-ketoisocaproate ( $p>0.05$, MannWhitney $U$ test).

\section{Discussion}

The present study shows that a 60 -min pretreatment of mouse islets with high concentrations of the sulfonylurea glipizide in the absence of any fuel causes loss of glucoseinduced amplification of insulin secretion (Fig. 1a). This loss of amplification is selective for glucose since it was not observed in the presence of $\alpha$-ketoisocaproate, $\mathrm{BCH}$ or monomethyl succinate (Fig. 1b). Rapid amplification of insulin secretion by both $\alpha$-ketoisocaproate and $\mathrm{BCH}$ has been observed previously $[8,9]$. The published experiments demonstrating amplification of insulin secretion by glucose did not include pretreatment of mouse pancreatic islets with a sulfonylurea in the absence of any fuel [1]. It is likely that the absence of fuel in conjunction with sulfonylurea-induced ATP consumption $[7,10]$ put a strain on energy metabolism in the beta cell mitochondria such that the addition of $30 \mathrm{mmol} / \mathrm{l}$ glucose or $10 \mathrm{mmol} / 1 \alpha$ ketoisocaproate was only sufficient to produce a small increase in the ATP:ADP ratio within $40 \mathrm{~min}$ (Table 1). Under these conditions, the responses of adenine nucleotides in islets were similar for $30 \mathrm{mmol} / 1$ glucose and $10 \mathrm{mmol} / \mathrm{l} \alpha$-ketoisocaproate; however, $\alpha$-ketoisocaproate stimulated insulin secretion, whereas glucose did not. This suggests that an increase in the cytosolic ATP:ADP ratio is unlikely to serve as an amplifying signal.

$\alpha$-Ketoisocaproate amplifies insulin secretion through its transamination with glutamate and its intramitochondrial degradation, which generates acetyl-CoA [8]. The transamination reaction yields $\alpha$-ketoglutarate and L-leucine. LLeucine stimulates the production of additional $\alpha$-ketoglutarate through activation of glutamate dehydrogenase in the beta cell mitochondria [3]. In the citric acid cycle, $\alpha$-ketoglutarate is converted into oxaloacetate (via the intermediates succinate, fumarate and malate), which reacts with acetyl-CoA to form citrate. Thus, $\alpha$-ketoisocaproate stimulates the citric acid cycle and enhances the export of citric acid cycle intermediates from the beta cell mitochondria to 
the cytosol [3]. The present study does not establish precisely which of the exported intermediates are involved in the $\alpha$-ketoisocaproate-induced amplification of insulin secretion. The very weak amplification of insulin secretion by monomethyl succinate (which is converted into succinate by ester hydrolysis in the beta cell) (Fig. 1b) suggests that the export of succinate, fumarate or malate does not mediate amplification. In addition, this weak response to monomethyl succinate seems to reflect insufficient formation of citrate, since succinate metabolism in mouse beta cells provides only small amounts of acetyl-CoA [3]. A major role of exported citrate (and isocitrate, which is formed from citrate in a reaction catalysed by aconitase) in the amplification of insulin secretion is also suggested by $\mathrm{BCH}$-induced amplification (Fig. 1b; [9]). The leucine analogue $\mathrm{BCH}$ activates glutamate dehydrogenase and amplifies insulin secretion solely, by increasing the production of $\alpha$-ketoglutarate [9]. In beta cells, $\alpha$-ketoglutarate can be converted into isocitrate and citrate by the reversal of the reactions catalysed by the enzymes isocitrate dehydrogenase and aconitase [3]. Glucose-induced formation of citrate and isocitrate requires the production of oxaloacetate in a reaction catalysed by pyruvate carboxylase in the beta cell mitochondria [3]. As sulfonylureas do not directly inhibit pyruvate carboxylase [11], inhibition of this enzyme by a low ATP:ADP ratio and/or a lack of acetyl-CoA [11, 12] might explain why glucose did not amplify insulin secretion from islets pretreated with glipizide in the absence of any fuel (Fig. 1a).

In conclusion, the present study supports the view that export of citrate and isocitrate from beta cell mitochondria to the cytosol plays a crucial role in the metabolic amplification of insulin secretion.

Acknowledgement We thank G. Henze-Wittenberg for excellent technical assistance.

\section{References}

1. Henquin J-C (2000) Perspectives in diabetes. Triggering and amplifying pathways of regulation of insulin secretion by glucose. Diabetes 49:1751-1760

2. Wollheim CB (2000) Beta-cell mitochondria in the regulation of insulin secretion: a new culprit in type II diabetes. Diabetologia 43:265-277

3. MacDonald MJ, Fahien LA, Brown LJ, Hasan NM, Buss JD, Kendrick MA (2005) Perspective: emerging evidence for signaling roles of mitochondrial anaplerotic products in insulin secretion. Am J Physiol Endocrinol Metabol 288:E1-E15

4. Yaney GC, Corkey BE (2003) Fatty acid metabolism and insulin secretion in pancreatic beta cells. Diabetologia 46:1297-1312

5. Roduit R, Nolan C, Alarcon C et al (2004) A role for the malonyl-CoA/long-chain acyl-CoA pathway of lipid signaling in the regulation of insulin secretion in response to both fuel and nonfuel stimuli. Diabetes 53:1007-1019

6. Panten U, Burgfeld J, Goerke F et al (1989) Control of insulin secretion by sulfonylureas, meglitinide and diazoxide in relation to their binding to the sulfonylurea receptor in pancreatic islets. Biochem Pharmacol 38:1217-1229

7. Detimary P, Gilon P, Henquin J-C (1998) Interplay between cytoplasmic $\mathrm{Ca}^{2+}$ and the ATP/ADP ratio: a feedback control mechanism in mouse pancreatic islets. Biochem J 333:269-274

8. Heissig H, Urban KA, Hastedt K, Zünkler BJ, Panten U (2005) Mechanism of the insulin-releasing action of $\alpha$-ketoisocaproate and related $\alpha$-keto acid anions. Mol Pharmacol 68:1097-1105

9. Liu Y-J, Cheng H, Drought H, MacDonald MJ, Sharp GWG, Straub SG (2003) Activation of the $\mathrm{K}_{\mathrm{ATP}}$ channel-independent signaling pathway by the nonhydrolyzable analog of leucine, BCH. Am J Physiol Endocrinol Metab 285:E380-E389

10. Elmi A, Idahl L-A, Sehlin J (2000) Relationships between the $\mathrm{Na}^{+} / \mathrm{K}^{+}$pump and ATP and ADP content in mouse pancreatic islets: effects of meglitinide and glibenclamide. Br J Pharmacol 131:1700-1706

11. White CW, Rashed HM, Patel TB (1988) Sulfonylureas inhibit metabolic flux through rat liver pyruvate carboxylase reaction. J Pharmacol Exp Ther 246:971-974

12. Curi R, Carpinelli AR, Malaisse WJ (1991) Hexose metabolism in pancreatic islets: pyruvate carboxylase activity. Biochimie $73: 583-586$ 